\title{
Effect of Different Rootstock for Higher Eggplant Production
}

\author{
Akm Quamruzzaman*, Ferdouse Islam and M. Nazim Uddin \\ Olericulture Division, Horticulture Research Centre, Bangladesh Agricultural Research Institute, Gazipur, \\ Bangladesh \\ Email: akmqzs@gmail.com
}

\begin{abstract}
A field experiment was conducted at Olericulture Division, Horticulture Research Center (HRC) of Bangladesh Agricultural Research Institute (BARI), Gazipur, Bangladesh, during the period from September 2018 to April 2019 to study the effect of different rootstock for higher eggplant production. Among the five treatments, it could be concluded that eggplant can be grafted on four rootstocks viz., BARI Begun-8 (BB8), EG203, S. sisymbriifolium (SS), F $121 \times 11)$ with desired scions- BARI Begun-5. In case of important yield and yield contributing characters viz., average fruit weight, fruit yield/ plant, fruit length and fruit width showed better performances when BB5 was grafted onto BB5/BB8 [186.67 g, $3.92 \mathrm{~kg} /$ plant, $10.37 \mathrm{~cm}, 8.20 \mathrm{~cm}]$ and BB5/F $1(21 \times 11)$ $[186.67 \mathrm{~g}, 3.98 \mathrm{~kg} /$ plant, $10.17 \mathrm{~cm}, 7.90 \mathrm{~cm}]$. Among the 4 grafted treatments, BB5 $/ \mathrm{F}_{1}(21 \times 11)$ (51.70 t/ha), BB5/BB8 (50.96 t/ha) and BB5/EG203 (45.61 t/ha) produced more than 45 t/ha. So, these three rootstocks may be selected considering higher yield. However, the study was conducted during winter season. So, to draw a complete conclusion it is needed to conduct this experiment during summer season.
\end{abstract}

Keywords: Rootstock, scion, compatibility, yield and eggplant production

\section{Introduction}

The advantages of vegetable grafting have been noticed by many workers. Grafts were used to induce resistance against low and high temperatures [26], enhance nutrient uptake [14] [12], increase synthesis of endogenous hormones, improve water use efficiency [32], reduce uptake of persistent organic pollutants from agricultural soils [29], improve alkalinity tolerance [13], raise salt tolerance [26], [31] and limit the negative effect of heavy metal toxicity. The scion variety affects size, yield, and quality of fruit in grafted plants, but rootstock effects can drastically alter these quality characteristics [3]. The quality characteristics might be affected by grafting as a result of the translocation of metabolites associated with fruit quality to the scion through the xylem and/or modification of physiological processes of the scion [32].

Eggplant (Solanum melongena L.), belonging to the family Solanaceae, is the most important and extensively consumed vegetable in Bangladesh. Brinjal is a very common and favorite vegetable in Bangladesh which has a link with the social, cultural and economic lives of rural people. It has been a staple vegetable in our diet since ancient times. Eggplant is rich in nutrition with appreciable amount of vitamins (A, B) and minerals like, B, Fe, I, Mg [30]. In Bangladesh, vegetable production is uniform round the year. Most of the vegetable are produced in the winter. Among the vegetables, eggplant is very important. Eggplant is the most important vegetable crop in respect of total acreage (50415 ha) and production (504817 ton) in Bangladesh with an average yield of 10.00 tons per hectare [5]. which is very low as compared to that other producing countries. The yield is quite low as compared to those advance country. One of the major reasons for low yield in Bangladesh is bacterial wilt disease. A report from India reveals that bacterial wilt can causes $27 \%$ losses eggplant [24]. To causal organism resistant rootstock is an effective technology to prevent the bacterial wilt. A report from Bangladesh indicated that grafting of eggplant on resistant rootstocks to present bacterial wilt [18].

Grafting has proved to be an efficient tool for increasing the yield, disease resistance and quality of a number of vegetable crops [2], [3], [15], [16]. Ideally, rootstocks may improve the yield and/or quality of the produce. This can be achieved by using rootstocks that have resistance to soil diseases or pests, tolerance to abiotic stress, selective absorption of available soil nutrients, or that confer a high degree of vigour to the scion [2], [3], [15], [16]. Here, we have tested the effects of grafting the eggplant cultivars 
onto different species of rootstocks and have found that improvements in the production of eggplant can be achieved by using this technique. Benefits realized through rootstock grafts often justify the challenges that successful production of grafted plants requires including synchronization and good germination rates of the rootstock and scion, and high rates of graft success and stand establishment after transplant.

Grafting is an ideal technique for vegetable production because scions with desirable fruit-producing traits that are also susceptible to soil-borne disease or climatic pressures can be grafted onto rootstock that is more resistant to these pressures. The resulting union often results in a more productive plant. Proper grafting practice may lead to the production of relatively large size fruit, increase yield, early harvest, and longest time of harvesting of fruits and conveniences in intercultural operation less damage to the fruit or plants. But in Bangladesh, majority of the grower do not get high quality fruit and high yield because of their ignorance about proper grafting technology practices. In a fertile soil with favorable condition, eggplants particularly grow continuously and produce large number of fruits. In this case, appropriate grafting method is necessary because to increase the yield and quality fruit of eggplant. Eggplant can be severely pruned without affecting the yield [19], [20].

Grafting can reduce cost of production, increase the yield and improve the fruit quality of fruit. In this work, we assess the potential vigour and influence on eggplant yield and fruit quality traits of BARI Begun-5 when it was grafted on BARI Begun-8, EG203, S. sisymbriifolium and $\mathrm{F}_{1}(21 \times 11)$ [hybrid] rootstocks. Hybrids of vegetable crops frequently present heterosis for vigour [22] and, in consequence have a potential utility as rootstocks. Apart from vigour, hybrids are used as rootstocks in many vegetable crops since they can incorporate resistances to pathogens from both parents [21], [16].

Rootstock-scion interactions are commonly observed in different crops [25], [10]. Increased earliness has also been reported for eggplant grafted onto two tomato hybrids [11] and in melon plants grafted onto Cucurbita rootstocks [25], [6]. Fruit quality is important for the marketability of fruit, and grafting can influence traits related to quality [1], [2], [3], [27], [28]. So, there is a positive impact of rootstock on quality and higher eggplant production. Keeping this information, our objective is to identify new potential rootstocks either OP or hybrid for quality and higher eggplant production.

\section{Materials and Methods}

The field experiment was conducted at Olericulture Division, Horticulture Research Centre, Bangladesh Agricultural Research Institute, BARI, Joydebpur, Gazipur during 05 September, 2018 to 05 April 2019.The experimental field was at $23.99^{\circ} \mathrm{N}$ Latitude and $90.41^{\circ} \mathrm{E}$ Longitudes having an elevation of 8.2 $\mathrm{m}$ from sea level.

\subsection{Plant Material}

The eggplant cultivar BARI Begun-5 (BARI released OP eggplant variety, Bangladesh) was used as the scion variety as well as the non-grafted control. Four rootstocks that included viz., BARI Begun-8, EG203, S. sisymbriifolium and $\mathrm{F}_{1}(21 \times 11)$ rootstocks, were evaluated (Table1). Data for morphological characters of the aerial part of these materials used as rootstocks were obtained from the database of the germplasm bank of the olericulture Division [Horticulture Research Centre (HRC), Bangladesh Agricultural Research Institute, Gazipur, Bangladesh (BARI)]. These data are useful to estimate the vigour of the rootstocks used.

Table 1. Plant materials used for the eggplant grafting experiments, type of material, and their origin

\begin{tabular}{lllll}
\hline Plant materials & Code & Species & Type of material & Origin \\
\hline BARI Begun-8 & BB-8 & Solanum melongena & Cultivated, commercial OP variety & BARI, Gazipur, Bangladesh \\
EG-203 & EG-203 & Solanum melongena & Commercial OP rootstock & World Vegetables Centre \\
S. sisymbriifolium & SS & S. sisymbrifolium & Wild & Bangladesh \\
F $_{1}(21 \times 11)$ & $\mathrm{F}_{1}(21 \times 11)$ & Solanum melongena & Cultivated, commercial F Fariety $_{1}$ & BARI, Gazipur, Bangladesh \\
BARI Begun-5 (Control) & BB-5 & Solanum melongena & Cultivated, commercial variety & BARI, Gazipur, Bangladesh \\
\hline
\end{tabular}




\subsection{Seed Germination}

Seeds of all genotypes [BB8, EG203, SS, $\mathrm{F}_{1}(21 \times 11)$ and BB5] were surface-sterilized for the grafting trial and sown on Petri dishes as detailed in [7], [8]. Gibberellic acid at $1 \mathrm{mgL}^{-1}$ was added to the sterile nutrient medium after filter sterilization. The $\mathrm{pH}$ of the medium was adjusted to 5.8 before sterilization at $120^{\circ} \mathrm{C}$ for $20 \mathrm{~min}$. In order to obtain uniform rootstock plantlets, and given that variability for seed germination rates and vigour was previously observed by us for some materials used in this work, seeds from all accessions were sown twice in two consecutive weeks [9]. Germinated seeds were subsequently transferred to seedling trays with cell sizes of $10 \mathrm{~cm} \times 10 \mathrm{~cm} \times 10 \mathrm{~cm}$ depth filled with mixture of Soil: Vermicompost (50: 50).

\subsection{Grafting}

The eggplant cultivar BB-5 was grafted onto BB-8, EG-203, SS, $F_{1}(21 \times 11)$ rootstocks using the cleft procedure described by Lee (1994). Plants at the 4-5 leaf stage (30-35 day old) were used as rootstocks except SS (45-50 days). The BB-5 scion source plants selected for grafting had a lower development stage (3-4 leaves; 25-30 days old). For grafting, the stem for both the scions and the rootstocks at right angles was cut using a razor blade. Rootstocks were cut over cotyledons and had a total length of 5-6 $\mathrm{cm}$. Scions of $1.5-2 \mathrm{~cm}$ with one or two small leaves were subjected to the rootstocks using a tiny grafting clip [9]. After grafting, plantlets were incubated within a plastic tunnel in a plastic tunnel with a mean air temperature of $28 \pm 3^{\circ} \mathrm{C}$ and $80-85 \%$ relative humidity for 8 days. Plantlets were subsequently acclimatized outside of the plastic tunnel for 7 days in open condition. Fifty plantlets of each rootstock were grafted.

\subsection{Growing Condition}

Forty-five to Fifty days-old healthy grafting plant were transplanted in experimental plots on 25 October, 2018. The experiment was laid out in a RCB design with three replications. The unit plot size was $7.5 \times 0.70 \mathrm{~m}$ and 10 plants were accommodated in a plot with a plant spacing of $70 \mathrm{~cm}$ apart in single row maintaining a row to row distance of $1 \mathrm{~m}$ with $30 \mathrm{~cm}$ drain. The land was fertilized with cowdung, N, P, K, S, Zn and B @ 10,000 100, 30, 75, 13, 1.5 and $0.8 \mathrm{~kg} / \mathrm{ha}$, respectively [4]. One third of the cow-dung and half of $\mathrm{P}$ and full of $\mathrm{S}, \mathrm{Zn}$ and $\mathrm{B}$ were applied during final land preparation. Rest of cow-dung and $\mathrm{P}$ and $1 / 3$ of $\mathrm{K}$ were applied as basal in pit. Entire amount of $\mathrm{N}$ and rest of $\mathrm{K}$ were applied in four equal installment starting from 20 days after transplanting. Rest three installments were applied at vegetative, flowering and initial fruiting stage. Irrigation, weeding, crop protection measures and other intercultural operations were done following standard practice.

\subsection{Data Recorded}

Data on germination (\%), graft success (\%), plants dead before initiation of fruit set (\%), plants dead at the end of the experiment (\%), stem diameter at last harvest $(\mathrm{cm})$, days to 1st harvest, plant height at first harvest $(\mathrm{cm})$, plant height at last harvest $(\mathrm{cm})$, number of marketable fruits, average fruit weight $(\mathrm{g})$, fruit length $(\mathrm{cm})$, fruit width $(\mathrm{cm})$, fruit length/ fruit width ratio, fruit yield/ plant $(\mathrm{kg})$, eggplant fruit and shoot borer (EFSB) infection (\%), fruit yield ( $\mathrm{t} / \mathrm{ha}$ ) were recorded from five randomly selected plants per Treatment.

\subsection{Data Analysis}

Data for each of the traits evaluated was analyzed via one-factor analysis of variance (ANOVA) using a fixed-effects model for the effect of rootstock treatment. For data expressed in percentage, the logarithmic transformation was applied. Significance of the treatment effects was obtained from the ANOVAs, and where the F-test proved significant $(\mathrm{P}=0.05)$, means were compared using the Duncan multiple-range test. 


\section{Results and Discussion}

\subsection{Germination, Graft Success and Plant Survival}

Germination of seeds sown in Petri dishes with GA3 containing medium for BB8 (BARI Begun-8), EG203, SS (S. sisymbriifolium), $\mathrm{F}_{1}(21 \times 11)$, BB5 (BARI Begun-5) (Control). At 8-10 days after sowing, BB8 and BB5 (Control) exhibited high percent germination (100\%) followed by $\mathrm{F}_{1}(21 \times 11)(96 \%)$, while lowest germination was obtained by SS (84\%) (Table 2). EG203 displayed moderate germination (92\%).

However, it was possible to obtain the necessary number of SS plantlets for the grafting experiments using a large amount of SS seeds sown in commercial substrate. Similar to our results, the commercial seed supplier warns that even under good conditions, SS germination may be erratic. The cleft grafting method proved highly efficient with success percentages $\geq 88 \%$ in all materials used (Table 2), while [9] mentioned that 'Black Beauty' and the interspecific hybrids $\mathrm{SI} \times \mathrm{SM}$ and $\mathrm{SM} \times \mathrm{SA}$ exhibited high percent germination $(\geq 90 \%)$. There was significant differences found in the success rate among the cultivated and wild rootstocks. BB8 and F1 $(21 \times 11)$ rootstocks, which had percentages of graft success that ranged from $96 \%$ [F1 $(21 \times 11))$ to $98 \%$ (BARI Begun-8]. In contrast, SS had a significantly lower percentage of success $(88 \%)$ with respect to the other rootstocks (Table 2). No over growth at the graft junction was observed for any rootstock-scion combination.

All transplanted grafted plants from the BB5/BB8 and BB5/F $(21 \times 11)$ developed well and survived (100\%) until the fruit set, while maximum mortality was obtained from BB5 (non-grafted plants) (20.00\%) followed by BB5/EG203 (13.33\%) and BB5/SS (6.67\%). Plants died at the end of the experiment was noticed in only BB5 (non-grafted plants) and it was $33.33 \%$, while other grafted plants were alive. Physiological disturbances induced by vascular bundle discontinuities at the graft union may lead to growth inhibition and high mortality; however, in this case, soil that was heavily infested with bacterial wilt may have been a major reason for the loss of plants. In fact, a high sensitivity to Ralstonia solanacearum has been reported for several accessions of S. melongena [9], [17].

In case of stem diameter at last harvest, the maximum diameter was obtained by BB5/BB8 $(2.65 \mathrm{~cm})$, followed by BB5/F1 $(21 \times 11)(2.60 \mathrm{~cm})$ and narrow diameter was obtained by BB5/SS $(2.36 \mathrm{~cm})$ followed by BB5/EG203 $(2.42 \mathrm{~cm})$.

Plant of all eggplant treatment grafted and non-grafted started $1^{\text {st }}$ harvest 104.00 - 111.33 days after sowing. It was observed that non grafted plants $1^{\text {st }}$ harvest was earlier than grafted ones. Early $1^{\text {st }}$ harvest was done in non-grafted plants after 104.00 days in BB5 (control). In case of grafted plants, earlier $1^{\text {st }}$ harvest was in BB5/BB8 (104.33 days) followed by BB5/F $\left.121 \times 11\right)$ (107.00 days), BB5/EG203 (108.00 days). The delayed $1^{\text {st }}$ harvest in grafted plant was observed in BB5/SS (111.33 days), while [9] mentioned that the first plants to flower and set fruit were from 'Black Beauty' grafted on $\mathrm{SI} \times \mathrm{SM}$ and $\mathrm{SM} \times \mathrm{SA}$ rootstocks. Fruit harvest for these plants began $50 \mathrm{~d}$ after transplanting, and fruit harvested until 57d after transplant were considered as early harvest fruit.

In this study it is clearly discussed that non grafted plants were earlier harvested compare to grafted plants. It is due to the delayed flowering in grafted plant, reported by [18].

Plant height at first harvest and plant height at last harvest showed significant difference among the different treatments (Table 2). Plant height at first harvest of all eggplant treatments of grafted and non-grafted were $57.67-64.33 \mathrm{~cm}$, while tallest plants were from BB5 (Control) and shortest were from BB5/SS. Same trend was observed in plant height at last harvest and it was $106.00 \mathrm{~cm}, 100.67 \mathrm{~cm}$, respectively, while [9] mentioned that the mean plant height among different treatments varied between 108.9 and $127.0 \mathrm{~cm}$ for the SMA and SI×SM rootstocks, respectively.

Significant differences among treatments were also evident for number of marketable fruits per plant (Table 3). The number of marketable fruits per plant ranged between 16.33 and 21.33 for 'BB5' respectively grafted onto SS and EG203 or $\mathrm{F}_{1}(21 \times 11)$ rootstocks, while non-grafted BB5 produced also 16.67 fruits. In case of average fruit weight, the heavier fruits $(186.67 \mathrm{~g})$ were produced from BB5/BB8 and $\mathrm{BB} 5 / \mathrm{F}_{1}(21 \times 11)$, while lightest fruits were produced from non-grafted BB5 (control). Significant differences among treatments were also evident for fruit yield/ plant, which followed a similar pattern. The fruit yield/ plant ranged between 2.58 and 3.98 for 'BB5' respectively non-grafted BB5 and grafted onto BB8 rootstock. [9] mentioned that the total fruits per plant ranged between 7.6 and 15.8 for 'Black Beauty' respectively grafted onto SMA and SI $\times$ SM rootstocks, while the total yield ranged between 3.4 kg plant-1. 


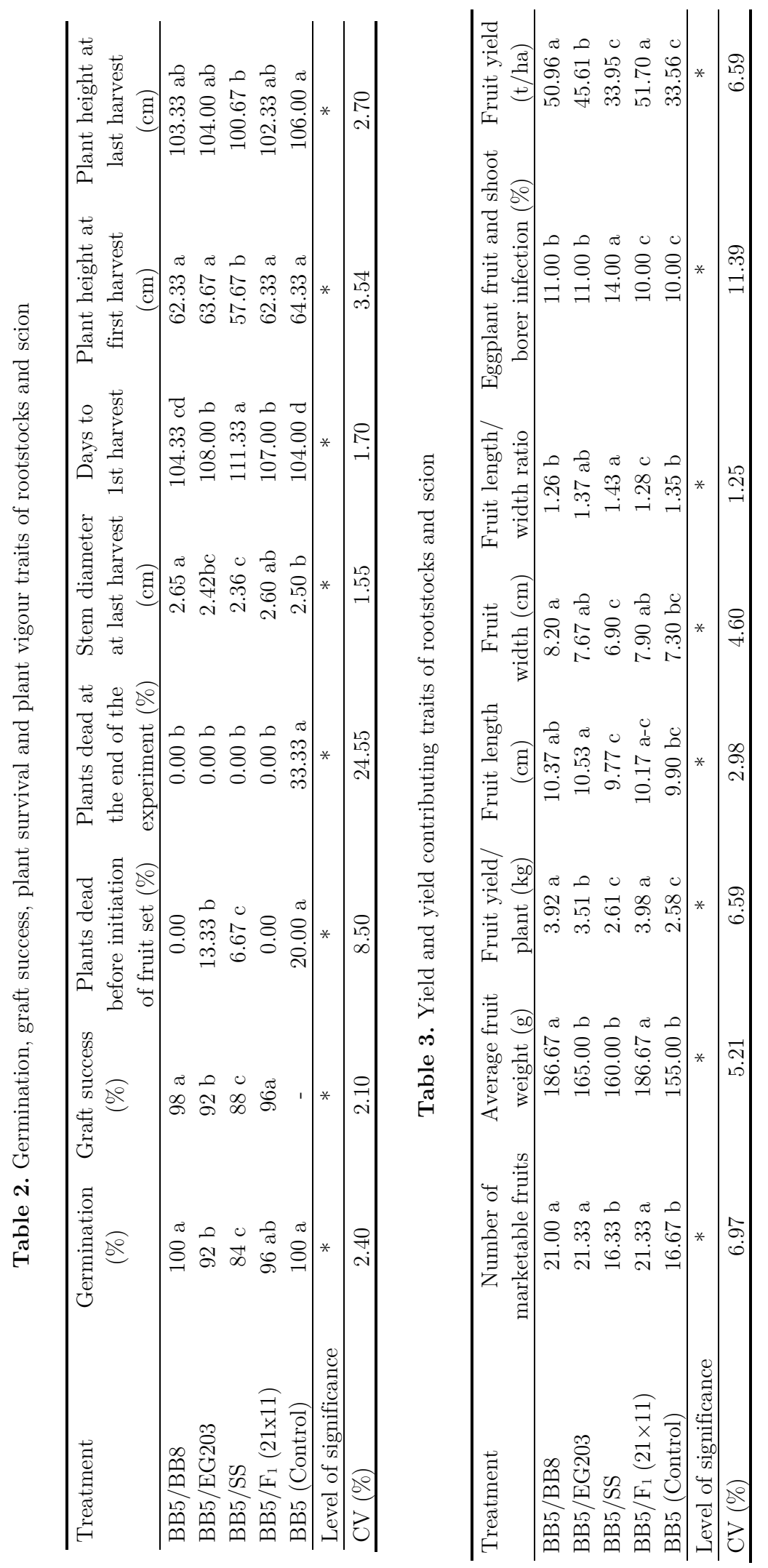


Fruit length ranged between 9.77 - $10.53 \mathrm{~cm}$ for those with SS and EG203 rootstocks, respectively (Table 3), while other larger length fruits were harvested from BB8 $(10.37 \mathrm{~cm})$ and $\mathrm{F}_{1}(21 \times 11)(10.17$ $\mathrm{cm}$ ). Non-grafted BB5 (Control) produced also lower length fruits $(9.90 \mathrm{~cm})$. Significant differences among treatments were also evident for fruit width, while maximum was obtained from BB8 rootstock $(8.20 \mathrm{~cm})$ followed by rootstocks $\mathrm{F}_{1}(21 \times 11)(7.90 \mathrm{~cm})$, EG203 $(7.67 \mathrm{~cm})$ and minimum was obtained from SS rootstock $(8.20 \mathrm{~cm})$.

In contrast, differences among treatments were found for fruit length and fruit width, which resulted in differences in the fruit length/width ratio. In this respect, fruit from 'BB5' grafted onto SS and EG203 rootstocks were significantly more elongated (length/width ratio of 1.43 and 1.37, respectively) than those from plants grafted onto BB8 and $F_{1}(21 \times 11)$ rootstocks plants which had fruit length/width ratios of 1.26 , and 1.28 , respectively.

Though the incidence of eggplant fruit and shoot borer (EFSB) infection is lower during winter season compare to summer season, but significant amount of infection was noticed in the study. Minimum infection by EFSB $(10.0 \%)$ was observed in 'BB5' while grafted onto $\mathrm{F}_{1}(21 \times 11)$ rootstock and nongrafted BB5 (Control) which is a very optimistic to select good treatment. The overall infection (\%) rate was $10.00-14.00 \%$, maximum infection $14.00 \%$ was observed in 'BB5' when grafted onto rootstock 'SS'. Other two rootstocks viz., BB8 and EG203 grafted 'BB5' were infected by ESFB @ 11.00\%.

The yield of marketable fruit per plot was converted into per hectare basis and was expressed in tones. Different grafted and non-grafted treatment significantly influenced the yield of production fruit per hectare (Table 3). The highest yield $(51.70 \mathrm{t} / \mathrm{ha})$ was recorded from BB5 when it was grafted onto rootstock $F_{1}(21 \times 11)$ followed by BB8 $(50.96 \mathrm{t} / \mathrm{ha})$. The yield ranged between $33.56-51.70 \mathrm{t} / \mathrm{ha}$ for 'BB5' when it was non-grafted (control) and was grafted onto rootstock $\mathrm{F}_{1}(21 \times 11)$, respectively. Moderate level yield (45 t/ha) was obtained from rootstock EG203. So, these three rootstocks viz., $\mathrm{F}_{1}$ $(21 \times 11)$, BB8, EG203 produced high fruit yield and may be selected best rootstocks for higher eggplant fruit yield.

Rootstock-scion interactions are commonly observed in different crops [25], [10] and it was observed that rootstock source can have an important effect on eggplant vigour, earliness, yield and fruit quality characteristics. In the absence of scion/rootstock incompatibility problems, grafted plants may also develop faster, thus contributing to earliness. In the present study, greater earliness was observed in the most vigorous rootstocks, i.e., the BB5/BB8. Increased earliness has also been reported for eggplant grafted onto two tomato hybrids [11] and in melon plants grafted onto Cucurbita rootstocks [25], [6]. It was also found that grafted plants with BB8, $\mathrm{F}_{1}(21 \times 11)$ and EG203 rootstocks had higher yield than non-grafted plants and that grafted plants with SS rootstocks had a much lower yield than other treatments, confirming that this latter rootstock has little value for improving eggplant yield. In contrast, BB8 and $\mathrm{F}_{1}(21 \times 11)$ rootstocks demonstrated positive benefits for agronomic performance in grafted eggplant. In this respect, grafting tomato plants onto an interspecific tomato rootstock also resulted in higher vigour when compared with tomato plants self-grafted or grafted onto other cultivated tomato rootstocks [10].

Fruit quality is important for the marketability of fruit, and grafting can influence traits related to quality [1], [2], [3], [27], [28]. Although no differences were found for most eggplant traits of apparent quality, but some differences were found for some relevant characters. For example, although fruit shape in eggplant is highly heritable and under genetic control, rootstocks influenced fruit length and fruit length/width ratios, possibly due to changes in the concentration of growth regulators induced by the rootstock.

\section{Conclusion}

Among the five treatments, it could be concluded that eggplant can be grafted on four rootstocks viz., BARI Begun-8 (BB8), EG203, S. sisymbriifolium (SS), F $(21 \times 11)$ with desired scions- BARI Begun-5. Incase of important yield and yield contributing characters viz., average fruit weight, fruit yield/ plant, fruit length and fruit width showed better performances when BB5 was grafted onto BB5/BB8 [186.67 g, $3.92 \mathrm{~kg} /$ plant, $10.37 \mathrm{~cm}, 8.20 \mathrm{~cm}]$ and BB5/F $(21 \times 11)[186.67 \mathrm{~g}, 3.98 \mathrm{~kg} /$ plant, $10.17 \mathrm{~cm}, 7.90 \mathrm{~cm}]$. Among the 4 grafted treatments, BB5/F $(21 \times 11)(51.70 \mathrm{t} / \mathrm{ha}), \mathrm{BB} 5 / \mathrm{BB} 8(50.96 \mathrm{t} / \mathrm{ha})$ and BB5/EG203 (45.61 t/ha) produced more than $45 \mathrm{t} / \mathrm{h}$. So, these three rootstocks may be selected considering higher 
yield. However, the study was conducted during winter season. So, to draw a complete conclusion it is needed to conduct this experiment during summer season.

\section{References}

1. A.A. Alexopoulos, A. Kondylis, H.C. Passam, 2007. Fruit yield and quality of watermelon in relation to grafting. J. Food Agric. Environ. 5, 178-179.

2. A.R. Davis, P. Perkins-Veazie, R. Hassell, A. Levi, S.R. King, X.P. Zhang, 2008a. Grafting effects on vegetable quality. Hort Science 43, 1670-1672.

3. A.R. Davis, P. Perkins-Veazie, Y. Sakata, S. López-Galarza, J.V. Maroto, S.G. Lee, Y.C. Huh, Z. Sun, A. Miguel, S. King, R. Cohen, J.M. Lee,2008b.Cucurbitgrafting.Crit. Rev. Plant Sci. 27, 50-74.

4. AKM. Quamruzzaman, Ferdouse Islam, M. Nazim Uddin and M.A. Z. Chowdhury. 2019. Evaluation of green eggplant hybrids for yield and tolerance to biotic stress in Bangladesh. Adv Agr Environ Sci. 2(1): 37-40. DOI: 10.30881/aaeoa.00020

5. Anonymous. 2017. Year Book of Agricultural Statistics of Bangladesh 2016. Bangladesh Bureau of Statistics, Ministry of Planning, Government of Peoples Republic of Bangladesh, Dhaka, Bangladesh. pp 249-290.

6. B. Fita, C. Picó, F. Roig, Nuez, 2004. Performance of Cucumis melo spp. agrestis as a rootstock for melon. J. Hortic. Sci. Biotechnol. 82, 184-190.

7. Gisbert, J. Prohens, F. Nuez, 2006. Efficient regeneration in two potential new crops for subtropical climates, the scarlet (Solanum aethiopicum) and gboma (S. macrocarpon) eggplants. N.Z. J. Crop Hortic. Sci. 34, 55-62.

8. Gisbert, P. Sánchez-Torres, M.D. Raigón, F. Nuez, 2010. Phytophthora capsici resistance evaluation in pepper hybrids: Agronomic performance and fruit quality of pepper grafted plants. J. Food Agric. Environ. 8, 116-121.

9. Gisberta, J. Prohensa, M. D. Raigónb, J. R. Stommelc, F. Nueza. 2011. Eggplant relatives as sources of variation for developing new rootstocks: Effects of grafting on eggplant yield and fruit apparent quality and composition. Scientia Horticulturae. 128: 14-22. doi:10.1016/j.scienta.2010.12.00

10. C. Leonardi, F. Giuffrida, 2006.Variation of plant growth and macro nutrient uptake in grafted tomatoes and eggplants on three different rootstocks. Eur. J. Hortic. Sci. 71, 97-101.

11. E.M. Khan, E.M.A. Kakava, D. Chachalis, C. Goulas, 2006.Effect of grafting on growth and yield of tomato (Lycopersicon esculentum Mill.) in greenhouse and open field. J. Appl. Hortic. 8, 3-7.

12. G. Colla, C.M.C. Suãrez, M. Cardarelli, Y. Rouphael. 2010a. Improving nitrogen use efficiency in melon by grafting. HortScience 45: 559-565.

13. G. Colla, Y. Rouphael, M. Cardarelli, A. Salerno, E. Rea. 2010b. The effectiveness of grafting to improve alkalinity tolerance in watermelon. Environ. Exp. Bot. 68: 283-291.

14. G. Pulgar, G. Villora, D.A. Moreno, L. Romero. 2000. Improving the mineral nutrition in grafted watermelon plants: nitrogen metabolism. Biol. Plant. 43: 607-609.

15. J.M. Lee, 1994. Cultivation of grafted vegetables I: current status, grafting methods and benefits. Hort. Science 29, 235-239.

16. J.M. Lee, M. Oda, 2003.Grafting of herbaceous vegetable and ornamental crops.Hortic. Rev. 28, 61-124.

17. L. Afouda, H. Bairney, H. Fanou, 2008. Evaluation of Amaranthus sp. and Vernonia amygdalina, and soil amendments with poultry manure for the management of root-knot nematodes on eggplant. Phytoparasitica 36, 368-376.

18. M. Ali, M.Z. Alam and M.A.M. Akanda.1994. Grafting: A technique of control soil-borne diseases of tomato and eggplant. IPSA-JICA publication No.4. Institute of Post graduate Studies in Agriculture (IPSA), Gazipur-1703. Bangladesh.pp.10.

19. M.A. Rahman, M.A Rashid, M.M. Hossain, M.A. Salam. 2002. Annual Report 2001-02, Horticulture Research Centre, Bangladesh Agricultural Research Inst., Gazipur, Bangladesh.

20. M.A. Rashid, M.A. Rahman, S.N. Alam, I. Faruk, H.S. Jasmine, N.A. Sultana, L. Black, J.F.Wang, N.S. Talckar, G. Luther and S.Miller, SISN: 40413, 2002.

21. M.C. Daunay, 2008. Eggplant. In: Prohens, J., Nuez, F. (Eds.), Handbook of plant breeding: Vegetables II. Springer, New York, NY, USA, pp. 163-220.

22. M.J. Bassett, 1986. Breeding vegetable crops. Avi Publishing Co, Westport, CT, USA.

23. M.M. Martinez-Rodriguez, M.T. Estañ, E. Moyano, J.O. Garcia-Abellan, F.B. Flores, J.F. Campos, 2008. The effectiveness of grafting to improve salt tolerance in tomato when an 'excluder' genotype is used as scion. Environ. Exp. Bot. 63: 392-401. 
24. P.P. Peddy, 1986.Analysis of crop losses in certain vegetables due to meloidogyne incognita. Int. Nematol. Net. NEWSL. 3(4): 3-5.

25. R. Cohen, C. Horev, Y. Burger, S. Shriber, J. Hershenhorn, J. Katanand, M. Edelstein, 2002. Horticultural and pathological aspects of Fusarium wilt management using grafted melons. HortScience 37, 1069-1073.

26. R.M. Rivero, J.M. Ruiz, L. Romero, 2003. Role of grafting in horticultural plants under stress conditions. J. Food Agric. Environ. 1, 70-74.

27. S. López-Galarza, A. San Bautista, D.M. Pérez, A. Miguel, C. Baixauli, B. Pascual, J.V. Maroto, J.l. Guardiola, 2004. Effects of grafting and cytokinin-induced fruit setting on colour and sugar-content traits in glasshousegrown triploid watermelon. J. Hortic. Sci. Biotechnol. 79, 971-976.

28. S. Proietti, Y. Rouphael, G. Colla, M. Cardrelli, M. de Agazio, M. Zacchini, E. Rea, S. Moscatello, A. Battistelli, 2008. Fruit quality of mini-watermelon as affected by grafting and irrigation regimes. J. Sci. Food. Agric. 88, $1107-1114$.

29. T. Otani, N. Seike. 2007. Rootstock control of fruit dieldrin concentration in grafted cucumber (Cucumis sativus). J. Pestic. Sci. 32: 235-242.

30. T.K. Bose, and M.G. Som. 1990.Vegetable Crops in India. Published by B. Mitra and Nayaprokash, 206 BidlranSarani, Calcutta, India.p. 249.

31. Y. He, Z. Zhu, J. Yang, X. Ni, D. Zhu. 2009. Grafting increases the salt tolerance of tomato by improvement of photosynthesis and enhancement of antioxidant enzymes activity. Environ. Exp. Bot. 66: 270-278.

32. Y. Rouphael, M. Cardarelli, G. Colla, E. Rea. 2008. Yield, mineral composition, water relations, and water use efficiency of grafted mini watermelon plants under deficit irrigation. HortScience 43: 730-736. 